\title{
Evaluation of Presepsin as a Predictive Marker in Women Undergoing ICSI
}

\author{
Bushra Rasheed Al-Azawea, Hayder A. L. Mossa, Liqaa R. Altamimi, and Lubna Amer Al-Anbary
}

\section{ABSTRACT}

Presepsin is an original biomarker with $13 \mathrm{kDa}$ molecular weight for identifying general inflammation and sepsis. The receptor for lipopolysaccharide/lipopolysaccharide binding protein (LPS/LBP) complexes -CD14 (cluster of differentiation) is uttered on the cell membranes of macrophage, monocyte, and granulocyte cells. The LPS/LBP-CD14 complex is freed into circulation by detaching CD14 from the cell membrane, generating a soluble-CD14. (s-CD14), that is triggered by the plasma proteases, producing sCD14- subtype, Presepsin. The assessment of the implication of Presepsin levels in women with infertility lacks in publications. Furthermore, in the present ART's drill, a precise examination to forecast ovarian response, that may have both amplified the effectiveness and condensed the prices of ART's, is still missing and there is a necessity for information on the expectedness of ovarian response in controlled ovarian stimulation. The goal of this study was to determine the ability of using Presepsin as a biomarker to evaluate the clinical pregnancy rate in a cohort of couples undergoing ICSI in a sample of Iraqi population.

Patients and Methods: Sixty infertile women selected for undergoing intracytoplasmic sperm injection, the patient's ovarian stimulation was by antagonist protocol accordingly to their clinical findings.

Results: The results of the study shows there was no significant difference in the serum Presepsin between pregnant and non-pregnant ladies, 421.57 (1534.65) versus 878.64 (1322.23), respectively $(P=\mathbf{0 . 8 7 5})$, Furthermore, there was no significant difference in follicular fluid Presepsin between pregnant and non-pregnant ladies, 1286.73 (1232.00) versus 0.00484 .15 (1467.00), respectively $(P=0.296)$.

Conclusions: It concluded that serum or follicular fluid Presepsin as a biomarker is a poor predictor of fertility outcome with no significant difference between pregnant and non-pregnant ladies.

Keywords: Presepsin, Clinical Pregnancy Outcome, Iraqi Women, ICSI.

\section{INTRODUCTION}

Infertility is a disease of the reproductive system defined by the failure to achieve a clinical pregnancy after 12 months or more of regular unprotected sexual intercourse [1].

Twenty to thirty percent of infertility cases are caused by male infertility, while $20-35 \%$ is due to female infertility, $25-40 \%$ is due to combined problems and, and in $10-20 \%$ of cases, the cause is unknown. The most common cause of female infertility is ovulatory problems which are generally manifested by sparse or absent menstrual periods [2].

For a woman to conceive, certain things should take place: intercourse must be around the time when the ovum is released from the ovary; has to be working at optimum levels; and her hormones must be well balanced. Fertilization problems occur mainly due to either structural problem in the Fallopian tubes or uterus or problems in ST) [4], [5].
Published Online: November 14, 2020

ISSN: $2684-5199$

DOI : 10.24018/ejbio.2020.1.6.116

Bushra Rasheed Al-Azawea

High Institute for Infertility Diagnosis and Assisted Reproductive Technologies/ AlNahrain University, Iraq.

Hayder A. L. Mossa*

High Institute for Infertility Diagnosis and Assisted Reproductive Technologies/ AlNahrain University, Iraq.

(e-mail: haydermossa@googlemail.com) Liqaa R. Altamimi

Baghdad Specialist Center for Fertility and IVF, Iraq.

Lubna Amer Al-Anbary

High Institute for Infertility Diagnosis and Assisted Reproductive Technologies/ AlNahrain University, Iraq.

*Corresponding Author

releasing follicles. Infertility may be attributed to hypothalamic pituitary factors which are hypogonadotrophic hypogonadism, also called hypothalamic pituitary failure (low follicular stimulating hormone FSH and low estrogen), normogonadotrophic hypogonadism (normal FSH and estrogen) which is due to hypothalamic -pituitary ovarian axis defect, hyper gonadotrophic hypogonadism (high FSH and low estrogen), also called ovarian failure [3].

Presepsin is a novel, $13 \mathrm{kDa}$ molecular weight biomarker for diagnosing systemic inflammation and sepsis. The circulating soluble form of CD14, a cluster of differentiation (CD) marker protein expressed on the surface of various cells including monocytes, macrophages, neutrophils, and B cells, is activated by plasma proteases, generating a 64 aminoacid-residue fragment named sCD14-subtype (sCD14-

While the biological role of Presepsin has not been completely elucidated, it is considered to be a regulatory 
factor capable of modulating cellular and humoral immune responses by interacting directly with $\mathrm{T}$ and $\mathrm{B}$ cells [6].

The clinical significance of the acute phase reactant, CRP, in the infertility population has been evaluated by some previous published reports [7], [8].

Even though diagnostic value of Presepsin in sepsis cases has been accepted, scarcepublications assessing the significance of this peptide in infertility population, and to the best of knowledge, is evaluating the presence of Presepsin in both plasma and follicular fluid (FF) and its effect on the reproductive performance of infertile couples by the present study.

\section{Patients, Materials And Methods}

Sixty infertile female patients aged range 18-41 years, BMI range (20-28.5) were recruited from the infertility clinic in High Institute for Infertility Diagnosis and Assisted Reproductive Technologies at Al- Nahrain University and from private fertility center (Baghdad Specialist Center) all undergoing controlled ovarian stimulation for IVF /ICSI treatment were by antagonist protocol accordingly to their clinical findings.

Hormonal analysis was performed at day two of the menstrual cycle, included serum FSH, LH, Estradiol $\left(\mathrm{E}_{2}\right)$, Prolactin, Testosterone, and Thyroid stimulating hormone.

All ultrasound scanning in assisted conception was performed transvaginally, while the Hysterosalpingography (HSG) was performed to exclude tubal blockage and to check for hydrosalpinges as it has a negative impact on the success rate, also to assess the integrity of the uterine cavity [9].

While a full history and physical examination for male partner were done by the urologist, a comprehensive semen analysis was performed for all males referred for assisted conception to ascertain the most appropriate technique suitable for the patient after (3-5) day of abstinence.

Transvaginal ultrasound guided oocyte retrieval was done 34-36 hours following the hCG injection under general anesthesia.

Blood samples were collected from each woman enrolled in ICSI procedure. The blood was allowed to coagulate for 30 minutes then centrifuged at $1500 \mathrm{rpm}$ for 15 minutes to separate the serum. The serum was quickly frozen and stored at $-20{ }^{\circ} \mathrm{C}$ until hormonal assays were performed [10].

\section{RESULTS}

Statistical analysis in the current study was based on the inclusion of 60 subfertile women and at the end of the study, positive clinical pregnancy was achieved in 28 ladies accounting for a rate of $46.7 \%$, as shown in Fig. 1. From now and then, results will be outlined according to pregnancy outcome so that characteristics of pregnant women will be contrasted with those women who failed to get clinical pregnancy.

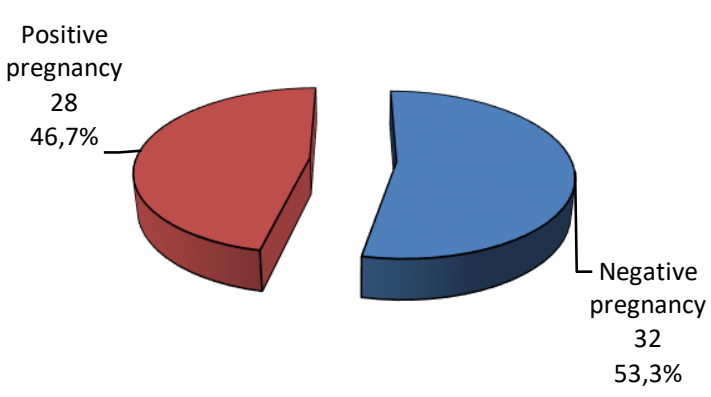

Fig. 1. Pie chart showing the pregnancy rate in subfertile women included in the present study.

Serum and follicular fluid marker, Presepsin, of subfertile women participating in the current study was described as median and inter-quartile range (IQR) due to non-normality distribution of these quantitative variables following performance of Kolmogorov-Smirnov test.

Results shows there was no significant difference in the serum Presepsin between pregnant and non-pregnant ladies, 421.57 (1534.65) versus 878.64 (1322.23), respectively ( $\mathrm{P}=$ $0.875)$. Furthermore, there was no significant difference in follicular fluid Presepsin between pregnant and nonpregnant ladies, 1286.73 (1232.00) versus 0.00484 .15 (1467.00), respectively $(\mathrm{P}=0.296)$ (Table 1 , Fig. 2$)$.

TABLE 1: SERUM AND FOLLICULAR FLUID PRESEPSIN IN ASSOCIATION WITH CLINICAL PREGNANCY OUTCOME

\begin{tabular}{ccccc}
\multicolumn{5}{c}{ WITH CLINICAL PREGNANCY OUTCOME } \\
\hline Characteristic & Total & $\begin{array}{c}\text { Positive } \\
\text { pregnancy } \\
n=60\end{array}$ & $\begin{array}{c}\text { Negative } \\
\text { pregnancy } \\
n=28\end{array}$ & $P$ \\
& & & & \\
\hline Serum Presepsin & 801.92 & 421.57 & 878.64 & $0.875 \dagger$ \\
Median (IQR) & $(1404.73)$ & $(1534.65)$ & $(1322.23)$ & $\mathrm{NS}$ \\
& $0.35-$ & $11.60-$ & $0.35-$ & \\
Range & 3300.76 & 3300.76 & 2985.34 & \\
FF Presepsin & & & & \\
Median (IQR) & 1155.81 & 1286.73 & 484.15 & $0.296 \dagger$ \\
& $(1392.00)$ & $(1232.00)$ & $(1467.00)$ & $\mathrm{NS}$ \\
Range & $53.00-$ & $245.00-$ & $53.00-$ & \\
\hline
\end{tabular}

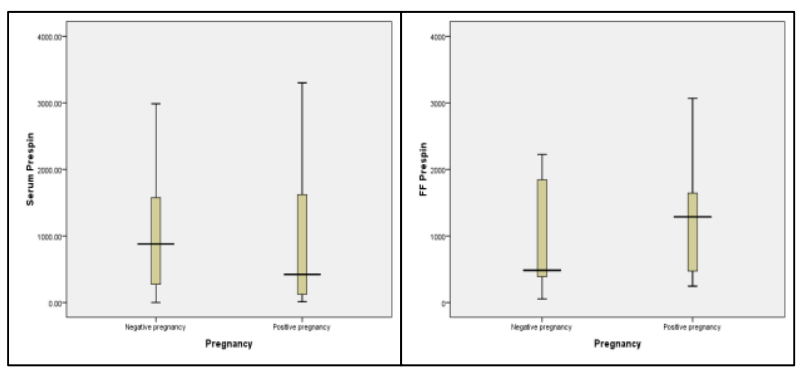

Fig. 2. Median serum and follicular fluid Presepsin in pregnant and nonpregnant ladies.

The serum and follicular fluid Presepsin were further analyzed aiming at finding the best cutoff value that can predict positive clinical pregnancy outcome. The cutoff value of serum Presepsin was $\leq 421.574$ with poor accuracy of $51.4 \%$, poor sensitivity of $52.6 \%$ and fair specificity of $68.2 \%$. The cutoff value of follicular fluid Presepsin was> 469.88 with poor accuracy of $59.6 \%$, good sensitivity of $73.7 \%$ and poor specificity of $50 \%$ (Table 2, Fig. 3). 
TABLE 2: CHARACTERISTICS OF ROC CURVE CONCERNING SERUM AND FOLLICULAR FLUID PRESEPSIN

\begin{tabular}{ccc}
\hline \multirow{2}{*}{ Characteristic } & \multicolumn{2}{c}{ Presepsin } \\
\cline { 2 - 3 } & Serum & Follicular fluid \\
\hline Cutoff & $\leq 421.57$ & $>469.88$ \\
AUC & 0.514 & 0.596 \\
$95 \%$ CI & $0.353-0.673$ & $0.431-0.746$ \\
Accuracy & 51.4 & 59.6 \\
$P$ & 0.881 & 0.300 \\
Sensitivity & $\mathrm{NS}$ & $\mathrm{NS}$ \\
Specificity & 52.6 & 73.7 \\
& 68.2 & 50.0 \\
\hline
\end{tabular}

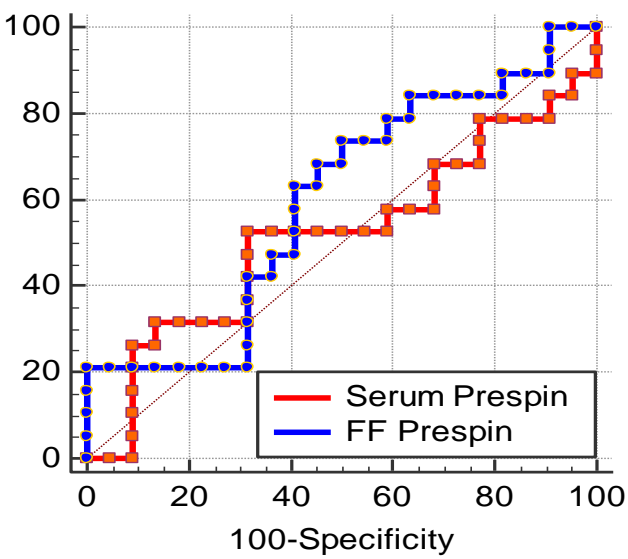

Fig. 3. Receiver operator characteristic (ROC) curve analysis to find the best serum and follicular fluid Presepsin cutoff values that predict positive clinical pregnancy outcome.

\section{Discussion}

In the present study, positive clinical pregnancy was achieved in 19 ladies accounting for a rate of $46.3 \%$. In one Iraqi study carried out at Fertility Center in An-Najaf governorate at Al-Sadr Medical City, the successful clinical pregnancy rate following ICSI was $28.9 \%{ }^{(11)}$, which is less than that of the present study. In another Iraqi study included 54 couples and conducted in Baghdad IVF infertility center, the clinical pregnancy outcome following ICSI was $20.4 \%$ [12] which is lower than that achieved in the current study.

However, a pregnancy rate of $51 \%$ was recorded by some Iraqi authors in a study carried out at out at the High institute for infertility diagnosis and Treatment / ALNahrain University and Specialist Fertility Department/ AlBonook hospital [13]. In nearby countries, the successful clinical pregnancy rate following ART has ranged from 21.5 to $33.9 \%$ [14], [15], indicating that the rate of positive clinical pregnancy in the current study is one of the best achieved rates.

However, in a number of fertility centers in the United States, the rate of positive clinical pregnancy has reached relatively high figures between $43.9 \%$ and $54.2 \%$ [16]. Therefore, the conductance of the current study and other studies in fertility center is aiming an increasing the rate of successful clinical pregnancy following ART procedures.

In this study, moreover, there was no significant difference in the serum Presepsin between pregnant and non-pregnant ladies. Furthermore, there was no significant difference in follicular fluid Presepsin between pregnant and non-pregnant ladies. The finding is in line Ovayolu et al., who found no significant association serum and follicular fluid Presepsin and clinical pregnancy outcome in sub fertile women undergoing ART [17].

The results are also consistent with the finding of another study carried out by Ovayolu et al. who described that follicular fluid Presepsin is a poor predictor of fertility outcome in poor and normal responders [18].

The clinical significance of the acute phase reactant, CRP, in the infertility population has been evaluated by some previous published reports [19], [20].

It has been accepted that not only the levels but also the trend of the inflammatory markers at the different stages of reproductive processes are of pivotal clinical significance. Indeed, literature assessment demonstrated that the variation pattern of plasma CRP levels on different days in women undergoing IVF has been investigated by several studies [21], [22]. However, we found that the inflammatory marker Presepsin is of no value with this regard.

\section{REFERENCES}

[1] Zegers-Hochschild F, Adamson GD, de Mouzon J, Ishihara O, Mansour R, Nygren K, Sullivan E, van der Poel S. International Committee for Monitoring Assisted Reproductive Technology (ICMART) and the World Health Organization (WHO) revised glossary of ART terminology. Fertil Steril, 2009;92: 1520-4.

[2] Turchi, P. 'Prevalence, Definition and Classification of Infertility' in Clinical Management of Male Infertility, 2014; 20: 5-11.

[3] De Roux, N. Dodé, C. 'Expert consensus document: European Consensus Statement on congenital hypogonadotropic hypogonadismpathogenesis, diagnosis and treatment', National Review of Endocrinogyl, Sep 2015; 11(9): 547-64.

[4] Mussap M, Noto A, Fravega M, Fanos V. Soluble CD14 subtype Presepsin (sCD14-ST) and lipopolysaccharide binding protein (LBP) in neonatal sepsis: New clinical and analytical perspectives for two old biomarkers. J Matern Fetal Neonatal Med. 2011; 24:12-14.

[5] Yaegashi Y, Shirakawa K, Sato N, Suzuki Y, Kojika M, Imai S, Takahashi G, Miyata M, Furusako S, Endo S. Evaluation of a newly identified soluble CD14 subtype as a marker for sepsis. J Infect Chemother. 2005; 11:234-238.

[6] Rey Nores JE, Bensussan A, Vita N, Stelter F, Arias MA, Jones M, Lefort S, Borysiewicz LK, Ferrara P, Labéta MO. Soluble CD14 acts as a negative regulator of human $\mathrm{T}$ cell activation and function. Eur $\mathrm{J}$ Immunol. 1999; 29:265-276.

[7] Levin I, Gamzu R, Mashiach R, Lessing JB, Amit A, Almog B Higher C-Reactive protein levels during IVF stimulation are associated with ART failure. J Reprod Immunol. 2007; 75:141-144.

[8] Seckin B, Ozaksit G, Batioglu S, Ozel M, Aydoğan M, Senturk B. The relationship between the change in serum high sensitivity Creactive protein levels and IVF success. Gynecol Endocrinol. 2012; 28:418-421.

[9] Asma Z. Fadhil, Thuraya Husamaldeen Abdullah, Hayder Ali Lafta Mossa. Evaluation of the effectiveness of transvaginal ovarian drilling under ultrasound guide in patients with resistant polycystic ovary syndrome to clomiphene citrate. International Journal of Research in Pharmaceutical Sciences (2019)., 10(2), 1556-1561.

[10] Fatimah Abdulrazaq Raheem, Hayder A. L. Mossa, Wasan A. Abdulhamed, Liqaa R. Altamimi. Assessment of Oxidative Stress Changes in Serum and Follicular Fluid in Relevance to GnRH Rival Protocol in Iraqi Infertile Ladies Undergoing ICSI. European Journal of Medical and Health Sciences (2019),1(5)1-5.

[11] Hussain SS, Al-Murshidi SY, Al-Fatlawi SJ. Association of Endometrial Thickness with Pregnancy Rate in Infertile Women Undergoing ICSI Program. International Journal of Pharmaceutical Research and Allied Sciences. 2018; 7(3):166-171.

[12] Ahmeid MS. Correlation between follicular fluid leptin and the pregnancy rate in women who underwent ICSI. International Journal of Current Research. 2015; 7(12): 24274-24277.

[13] Fadhil SS., Selman MO., Al-Obaidi MT. Study the Number of Transferred Embryos Increase the Pregnancy Rates in Fresh ICSI-ETcycles. Global Journal of Bioscience and Biotechnology. 2017; 6 (4): S1-S5. 
[14] Ashrafi M, Jahanian Sadatmahalleh S, Akhoond MR, Ghaffari F, Zolfaghari Z. ICSI Outcome in Infertile Couples with Different Causes of Infertility: A Cross-Sectional Study. Int J Fertil Steril. 2013;7(2):88-95.

[15] Eftekhar M, Mohammadian F, Yousefnejad F, Molaei B, Aflatoonian A. Comparison of conventional IVF versus ICSI in non-male factor, normoresponder patients. Iran J Reprod Med. 2012;10(2):131-136.

[16] Zagadailov P, Hsu A, Seifer DB, Stern JE. Differences in utilization of Intracytoplasmic sperm injection (ICSI) within human services (HHS) regions and metropolitan megaregions in the U.S. Reprod Biol Endocrinol. 2017;15(1):45.

[17] Ovayolu A, Özdamar Ö, Gün İ, et al. Can blood or follicular fluid levels of Presepsin predict reproductive outcomes in ART: a preliminary study. Int J Clin Exp Med. 2015;8(5):7983-7988.

[18] Ovayolu A, Özdamar Ö, Gün İ, et al. The assesment of follicular fluid Presepsin levels in poor ovarian responder womenandits relationship with the reproductive outcomes. Int J Clin Exp Med. 2015;8(6):99619966.

[19] Seckin B, Ozaksit G, Batioglu S, Ozel M, Aydoğan M, Senturk B. The relationship between the change in serum high sensitivity Creactive protein levels and IVF success. Gynecol Endocrinol. 2012; $28: 418-421$.

[20] Almagor M, Hazav A, Yaffe H. The levels of C-reactive protein in women treated by IVF. Hum Reprod. 2004; 19:104-106.

[21] Orvieto R, Chen R, Ashkenazi J, Ben-Haroush A, Bar J, Fisch B. CReactive protein levels in patients undergoing controlled ovarian hyperstimulation for IVF cycle. Hum Reprod. 2004; 19:357-359.

[22] Wunder DM, Kretschmer R, Bersinger NA. Concentrations of leptin and C-reactive protein in serum and follicular fluid during assisted reproductive cycles. Hum Reprod. 2005; 20:1266-1271. 